\title{
LA FILOSOFÍA ANTE EL ROSTRO DE LA MUERTE: ¿ES POSIBLE UNA NUEVA CONVIVENCIA?
}

\author{
The Philosophy in the Face of Death: Is a new \\ Coexistence Possible?
}

\section{A filosofia diante do rosto da morte: é possível uma nova convivência?}

Jaime Villanueva Barreto1

"La mayoría flotan desgraciados entre el miedo de la muerte y los tormentos de la vida; no quieren vivir y no saben morir." Séneca

\begin{abstract}
Resumen:
Este trabajo parte de la especificidad del Perú y Latinoamérica para indagar la posibilidad de una nueva convivencia post-pandemia. Desde una mirada que pretende integrar la tradición fenomenológica con la filosofía en perspectiva latinoamericana y la tradición cultural andina, queremos sacar a luz sus coincidencias en un diálogo acerca de un tema tan universal como humano: la vida y la muerte. Nuestra reflexión propone replantear nuestra forma de convivencia basándonos en la crítica latinoamericana del lugar-que-da-verdad ellacuriano y la sabiduría popular scanonniana para proponer el Sumak Kawsay como un nuevo modo de relacionarnos entre los latinoamericanos y los seres humanos en general.
\end{abstract}

Palabras clave: filosofía, fenomenología, filosofía latinoamericana, Perú, vida Abstract:

1 Licenciado en Filosofía (Universidad Nacional Mayor de San Marcos). Doctor en Filosofía (Pontificia Universidad Católica del Perú). Profesor principal de la Universidad Nacional Tecnológica de Lima Sur y profesor asociado del Departamento de Filosofía de la Universidad Nacional Mayor de San Marcos. Miembro de la Escuela Internacional de Filosofía Intercultural, de la Asociación Sudamericana de Filosofía y Teología Intercultural, del Círculo Latinoamericano de Fenomenología y del Círculo Peruano de Fenomenología y Hermenéutica. Autor del libro La fenomenología como afirmación de un nuevo humanismo (Lima, UNMSM-USIL, 2014). Correo electrónico: jvillanuevab_ac@unmsm.edu.pe ORCID: https://orcid.org/0000-0002-1168-8379 
This paper considers the specificity of Peru and Latin America in order to investigate the possibility of a new post-pandemic coexistence. From a perspective that seeks to integrate the phenomenological tradition with the philosophy in Latin American perspective and the Andean cultural tradition, we want to expose their coincidences in a dialogue about a topic both universal and human: the life and the death. Our reflection proposes to rethink our way of coexistence based on the Latin American critique of the Ellacurian "lugar-que-da-verdad" and the Scanonian "sabiduría popular" to propose the Sumak Kawsay as a new way of relating among Latin Americans and human beings in general.

Key words: philosophy, phenomenology, Latin American philosophy, Peru, life

\begin{abstract}
Resumo:
Este trabalho parte da especificidade do Peru e América Latina para indagar a possibilidade de uma nova convivência post pandemia. A partir de um olhar que pretende integrar a tradição fenomenológica com a filosofia em perspectiva latino-americana e a tradição cultural andina, queremos expor suas coincidências em um diálogo sobre um tema tão universal como humano: a vida e a morte. Nossa reflexão propõe repensar nossa forma de convivência baseando-nos na crítica latino-americana do lugar-que-dá-verdade ellacuriano e a sabedoria popular scanonniana para propor o Sumak Kawsay como um novo modo de nos relacionar entre os latino-americanos e os seres humanos em general.
\end{abstract}

Palabras chave: filosofia, fenomenologia, filosofia latino-americana, Peru, vida

\section{Un pensar situado}

La filosofía surge como una necesidad humana de afirmar la vida. Es un grito de libertad para poder adentrarse en las profundidades de la existencia sin tener que pedir permiso ni dar cuenta a nadie, más que a la verdad, de sus resultados. Una muestra palpable de ello la tenemos cuando, en los años treinta del siglo pasado, la muerte rondaba Europa y el anciano filósofo Edmund Husserl denunció a la Krisis de las ciencias como expresión de la Krisis de la humanidad en su conjunto ${ }^{2}$.

2 Cfr. Edmund Husserl, La crisis de las ciencias europeas y la fenomenología trascendental
En un tiempo de penurias como ese, cuando la amenaza a su propia vida asomaba, propuso la vuelta al olvidado fundamento del mundo de la vida (Lebenswelt). Es decir, una apuesta por ella frente a la tragedia anunciada por el nazismo.

En estos momentos en que no solo Europa, sino el planeta entero se ve amenazado por la muerte, no producto de una inminente guerra, sino de una pandemia que no solamente amenaza, sino que ha cambiado de un momento para otro, y tal vez para siempre, nuestro modo de relacionarnos, de

(Buenos Aires: Prometeo Libros, 2008) 
vincularnos con nosotros mismos, con los otros y con el mundo, cabe preguntarse ¿qué papel le cabe a la filosofía como afirmación de la vida? ¿Qué nos puede decir ella sobre lo que estamos viviendo? ¿En qué medida nos debe convocar a "detenernos a pensar"? ¿Qué nos puede decir ella sobre nuestro mundo de la vida? Son solo algunas preguntas que convocan nuestra reflexión y que debemos abordar, al menos como ensayos iniciales de comprensión de todo lo que nos está tocando vivir.

Lo primero que podemos afirmar en este sentido es que a la filosofía ya no le cabe el papel que le asignara Hegel de ser como el Búho de Minerva que alza vuelo al anochecer. Más bien, creo que es tiempo de, como quería nuestro Augusto Salazar Bondy, cambiar de ave y asociar a la filosofía con el gallo que canta con la aurora al amanecer, es decir, que se anticipa y señala el camino con la luz del día. Una filosofía atenta a los signos de los tiempos y que, como sucediera hace cinco siglos, empiece a imaginar una nueva figura del mundo y una nueva manera de estar en él.

Para ello, creemos que la fenomenología se muestra como una maestra. Con su método zigzagueante puede ir avanzando hacia la comprensión de lo que está por venir, pero interrogando retrospectivamente por los orígenes de lo que nos ha conducido a lo que estamos viviendo. Esto quiere decir que la respuesta siempre estará en nosotros mismos y la posibilidad de constituir nuevos sentidos que nos coloquen en una relación diferente con el mundo que habitamos. La inspectio sui que reclamaba Husserl se hace urgente en un tiempo de penurias como este. La tarea que le cabe a la fenomenología es la de instituirse, como quería su fundador, como "la humanidad que lucha por su auto-comprensión".

Este llamado a la auto-comprensión pasa, sin embargo, por no dejar de examinar cuales son las condiciones no sólo biológicas, como una pandemia, que nos han conducido al desastre que estamos viviendo. Porque esto no se trata meramente de una pandemia, sino que esta ha revelado lo que ya todos intuíamos de alguna manera. La estructura profundamente excluyente, desigual, egoísta y rapaz de la sociedad en la que vivimos.

Nos toca como filósofos y especialmente a quienes vemos en la fenomenología un poderoso instrumento de reflexión y crítica, rehacer para nosotros lo que Husserl hizo en su tiempo para una Europa que se veía traicionada en su ideal y desangrándose producto de un vaciamiento de sentido que los condujo a una mera "zoología de los pueblos". Ya en su ancianidad, Husserl, retomó las fuerzas del origen 
y nos legó su testamento filosófico en que hace un llamado desesperado a los filósofos para que se instituyan en funcionarios de la humanidad.

La vuelta al mundo de la vida, propuesta por Husserl, es posible entenderla también como un regreso a la génesis de donde todo surge, la vida misma expresada en nuestras acciones cotidianas que a cada momento la afirman. Al contraponerlas a los mundos imaginarios y abstractos legados por una tecnociencia de carácter meramente instrumental y cada vez más alejada del ideal de la verdad, que le da sentido a la vida humana, Husserl reconoce el valor de ésta y la necesidad de una vuelta a ella, a su interrogación y descripción en sus orígenes como modo de revertir la Krisis. Es decir, el camino retrospectivo de la Rückfrage es el que le brinda absoluta radicalidad al pensamiento filosófico para reencontrarse consigo mismo y asumir con renovada fuerza la misión histórica que le corresponde.

Hoy nuestro deber es ir más allá de la coyuntura, el análisis rápido, la ansiedad de tener algo que decir o la simple voracidad de ser el primero en ser publicado. Nuestro trabajo es distinto, consiste en ir hacia el origen constitutivo de sentido para poder describirlo y así dar cuanta de él, captar sus falencias y denunciarlas. Eso pasa por atravesar por la exigencia más importante que nos hace Husserl, la de que todo filósofo deba, al menos, una vez en la vida atravesar por el infierno de la epojé cartesiana ${ }^{3}$. Es decir, poner en cuestión los fundamentos mismos de sus creencias para, solo así, poder elevarse al cielo de una filosofía rigurosa.

Tenemos entonces una doble exigencia a la que no podemos renunciar. Por un lado, la de un sano escepticismo aún respecto de nuestras creencias más firmes y, por el otro, la de la rigurosidad en el pensar. Esto supone lo que será el legado más profundo de la fenomenología, habernos mostrado el método apropiado para pasar de la actitud natural, dogmática, objetivante a la actitud filosófica por medio de la epojé. Esta nos abre un mundo nuevo en el que, por fin, podemos entender que somos responsables por todas nuestras constituciones de sentido. En otras palabras, nada de lo que pase con nosotros nos puede ser ajeno, pues somos nosotros los que hemos constituido este tipo de mundo y sociedad.

Ese es el sentido último de la responsabilidad filosófica, el hacerse cargo por nuestras constituciones de sentido, incluidas las históricas. Saber que somos nosotros, en nuestro hacer y dejar de hacer cotidiano, los únicos responsables de lo que nos sucede como comunidad humana. La vuelta al

3 Cfr. Husserl, La crisis de las ciencias europeas y la fenomenología trascendental, 117. 
mundo de la vida implica la vuelta a la historia y hacerse cargo de ella mediante una reflexión y crítica profundas. En ese sentido, cabe empezar esta reflexión por lo que tenemos más a la mano, es decir, nuestro propio mundo circundante.

\section{EI Perú ante la muerte}

¿Qué tipo de mundo hemos constituido, por ejemplo, los latinoamericanos y en mi caso personal, los peruanos? Esta pregunta resulta urgente en el contexto en el que nos ha tocado vivir la pandemia. Nos interpela acerca de cómo, mediante qué experiencias hemos llegado a constituir un tipo de sociedad que ahora se ve confrontada al desastre y escándalo que supone la pérdida de cada vida humana, no solo producto del virus, sino también de la indolencia, indiferencia o ineficiencia de un Estado absolutamente incapaz.

En las últimas décadas hemos vivido, en mi país, bajo la ilusión falaz de la prosperidad que nos daban las cifras macroeconómicas. Nunca pudo estar mejor aplicada la reflexión husserliana acerca de la matematización de la naturaleza y su impacto en la vida concreta de los hombres. En cifras y números todo parecía ir aparentemente bien y muchos de nuestros países, fieles cumplidores de los mandatos neoliberales, habían puesto bajo la alfombra todas las carencias e inequidades históricas, pues lo importante eran las cifras y los números. Como diría el poeta, olvidaron poner el acento en el hombre.

Ahora, cuando tenemos a la muerte asechándonos, han salido a relucir todas nuestras miserias. Se trataba de una economía que había escondido que esa prosperidad se asentaba en la precariedad del informal, de aquel que tiene que trabajar muchas horas al día, sin ningún tipo de seguridad o derecho, para poder vivir del día a día. Una sociedad que llamó a los informales con el eufemismo de emprendedores que no es otra cosa que dejar a esos millones de personas solas a su suerte luchando por su supervivencia. Pasamos de ser ciudadanos a ser emprendedores y con ellos perdimos todos nuestros derechos.

Este año, los peruanos, cumplimos 200 años de intentos por ser una república, sin lograrlo. Una república fallida es el Perú. Hace pocos meses se reveló la infamia cometida por un grupo de traidores, liderados por el propio presidente de la república de ese momento, que se vacunaron de manera irregular mostrándonos el peor rostro de nuestra élite. El egoísmo, la cobardía, la mendacidad, la felonía, la mediocridad y la corrupción han sido las constantes históricas desde nuestra independencia. Todas ellas afloraron en los tres grandes momentos de desastre nacional que vivimos los peruanos, a saber, la guerra con Chile, el terrorismo 
de Sendero Luminoso y la pandemia que hoy sufrimos. En todas ellas tuvimos siempre una élite de caciques señoriales que volvieron la espalda a la nación y velaron por sus intereses mezquinos y sus grandes negociados. Nos vendieron una idea de una patria libre, igualitaria y justa, nos exigieron mil sacrificios para construirla, sin embargo, ellos estuvieron siempre dispuestos a ser los primeros en traicionarla.

La nuestra se constituye en una sociedad de la desconfianza donde el manejo de los símbolos es muy difícil, nos hemos acostumbrado a que la gente aplauda y a la vez dude del que le habla. Buscamos esperanza y también al culpable. Esto pese a los muchos intentos por parte del Estado por construir una identidad nacional, ha fracasado, pues siempre se hizo desde arriba y como una imposición. Los peruanos aprendimos a de decir que sí cuando es no, como un modo de resistir el avasallamiento de los dominadores.

En una perturbadora novela, Guillermo Thorndike hace reflexionar a uno de sus personajes principales:

"Carecemos de identidad histórica, hemos traicionado nuestra antigua lengua, nos hemos olvidado de los dioses propios y hemos adoptado divinidades ajenas no siempre de la manera más honesta. Nos damos golpes en el pecho, cumplimos con las formalidades y después hacemos lo que nos da la gana. Hemos delimitado claramente los compartimentos estancos de la vida: mi amor por la mujer en la persona de mi madre, a la cual respeto, pero todas las demás son utilizadas, maltratadas, Unas putas. Mi amor por la madre de mis hijos pero traición a mi esposa. Mi respeto al padre, al Señor Morado: un día de procesión y trescientos sesenta y cuatro de corrupción." 4

En suma, somos y no somos. Mantenemos un discurso que sea aceptado para evitar el rechazo, pero es siempre difícil saber exactamente qué piensa un peruano. Tenemos un tipo de moral que no respeta al Otro como alguien diferente, sino que genera relaciones de poder autoritario en las que no todos somos iguales. Ante delitos tan atroces como los perpetrados durante la época del terrorismo o la vacunación irregular a costa de la vida de miles de peruanos, sus responsables piden impunidad o nunca son castigados. Dentro de esta mentalidad hay vidas que son prescindibles en el Perú.

Precisamente, Salomón Lerner Febres, cuando en un breve discurso ante el presidente de la república hace entrega al país del voluminoso Informe Final de la Comisión de la Verdad y reconciliación que presidió y donde se detallan los actos de barbarie más

4 Guillermo Thorndike, La revolución imposible (Lima: Mosca Azul Editores, 1988), 48. 
terribles de nuestra historia cometidos entre 1980 y el 2000, sostiene:

"Se nos pidió averiguar la verdad sobre la violencia, señor Presidente (...) y la lista, que entregamos hoy a la nación es demasiado grande como para que en el Perú se siga hablando de errores o excesos de parte de quienes intervinieron directamente en esos crímenes. Y la verdad que hemos encontrado, es también, demasiado rotunda como para que alguna autoridad o ciudadano cualquiera pueda alegar ignorancia en su descargo. El informe que entregamos expone, pues, un doble escándalo: el del asesinato, la desaparición y la tortura a gran escala y el de la indolencia, la ineptitud y la indiferencia de quienes pudieron impedir esta catástrofe humanitaria y no lo hicieron." ${ }^{5}$

Cabe preguntarse entonces por las fuentes de esta profunda insensibilidad ética que nos llevó a tanto horror. Lo cierto es que la exclusión, la violencia, el autoritarismo y la corrupción son actos de nuestro vivir cotidiano. Sin embargo, lo más terrible de todo esto es que el cansancio, del que hablaba Husserl como el mayor peligro de la humanidad europea, pareciera haberse apoderado de nosotros. Todos parecemos conformados a vivir en ese sistema al que ninguna filosofía pudo hacerle frente. Incluso el intento más

5 Salomon Lerner Febres, La rebelión de la memoria (Lima: Idhepucp, 2004), 147. serio nacido en Latinoamérica como el de la filosofía de la liberación no logró calar con la profundidad debida en todos nuestros pensadores.

La única manera de hacer frente a tanto desastre es retomar las fuerzas del origen, de la vida misma, y de manera comunitaria plantearnos estos acuciantes problemas una y otra vez. Cada país latinoamericano estará viviendo su propio drama, pero muchos de nuestros problemas son constitutivos de una historia común o con muchos vasos comunicantes.

\section{Filosofar en perspectiva Latinoamericana y el lugar-que-da-verdad}

Por eso, hoy más nunca, una tarea impostergable para nosotros es pensar en qué medida el ejercicio de la filosofía que hacemos puede responder a la situación límite en la que parecemos encontrarnos. Hasta qué punto, nuestra academia será capaz de responder a esos retos o si seguiremos refugiándonos en el comentario, la exégesis y la escolástica. Creo que la demanda más importante de nuestro tiempo es la exigencia, ya hecha por el P. Juan Carlos Scannone, de filosofar en perspectiva latinoamericana. Esto significa el reconocimiento de la especificidad de los modos de vida y cultura Latinoamericana en el debate filosófico. 
Esta formulación permite reconocer la especificidad propia de Latinoamérica sin que por eso se caiga en un particularismo relativista.

$\mathrm{Y}$ es que la fenomenología tampoco es ajena a esta postura. Husserl mismo fue siempre consiente de la relatividad de la universalidad en los asuntos humanos. Una ciencia del mundo de la vida, nos enseña en la Krisis, es una ciencia sobre lo relativo-subjetivo, pero precisamente en esa relatividad se encuentra yacente su universalidad. Tal vez Merleau-Ponty aclara mejor esto con su noción de "universal lateral", donde no se puede postular ninguna sustancia inmutable o cultura superior. Toda cultura, al contrario, acaece en el mundo de la historia y sus estructuras invariantes solo pueden ser entendidas en la medida en que el universal alcanzado nunca puede ser una imposición. Por eso, seguiremos insistiendo en el valor de la fenomenología para la comprensión de nuestra propia situación.

Volviendo a Scannone, lo que debemos buscar es una filosofía que tenga validez universal pero que esté pensada desde Latinoamérica, teniendo en cuenta su historia, situación social y cultura para poder resolver los problemas teóricos y prácticos que surgen en el continente. Y la vía para lograrlo se centra en la compresión de

6 Maurice Merleau-Ponty, Signos (Barcelona: Seix Barral, 1964), 142. la sabiduría de los pueblos, es decir, la sabiduría popular.

"La sabiduría popular latinoamericana más allá de posibles alienaciones de las que no está a priori preservada, implica un sentido de la vida (del mundo, del hombre, de Dios) y una racionalidad sapiencial que la filosofía puede y debe explicitar y articular conceptualmente, en servicio del aporte filosófico universal de América Latina."

El sujeto de esa sabiduría popular es un 'nosotros', un sujeto comunitario denominado como pueblo; viene a ser una comunidad orgánica donde cada miembro tiene una función y tarea específica distinta. Debido a que es una comunidad, no hay un privilegio exclusivo y excluyente, sino que se da una participación activa de todos los integrantes, se debe resaltar que el pertenecer a un pueblo no les quita a los individuos su especificidad. Con ello, tenemos el camino señalado para un nuevo punto de partida del filosofar latinoamericano.

De este modo, la sabiduría popular constituye la mediación entre cultura, religiosidad, símbolos, pensar filosófico y todo lo que forma parte de una cultura; implica además el sentido último de la vida de acuerdo a lo propio de la sabiduría del pueblo latinoamericano.

7 Juan Carlos Sacannone, "Un nuevo punto de partida en la filosofía latinoamericana", Revista Stromata (1980): 26. 
La sabiduría popular no está limitada al ámbito académico, sino que su relación es fundamentalmente con la simbología cotidiana, como el espacio de lo religioso, político y poético. Los símbolos cobran importancia ya que son los que estructuran al pueblo junto a su cultura y modos de vida, los actualiza en su praxis histórica.

Es así que la sabiduría popular se constituye en este necesario punto de partida que, es a la vez, el del mundo de la vida cotidiano, pues como dice Scannone: "condensan la memoria histórica, la experiencia de la vida y del sentido, las esperanzas y aspiraciones de un pueblo. Allí se dan en uno lo que es humano-universal y lo que es propio y originario -aunque no necesariamente exclusivo- de ese pueblo." ${ }^{8}$ Supone entonces una vuelta al fondo mismo del mundo cotidiano de donde esa sabiduría popular emerge y se mantiene. Es nuestro pasado y presente viviente que está ahí ante nosotros interpelándonos.

Más aún en un momento como este en que nos enfrentamos al agotamiento de una manera de comprender y estar en el mundo. La pandemia nos revelado en toda su magnitud la Krisis que ya, incluso Husserl, diagnosticó con tanta precisión. Se constituye en nuestro deber pensar-con y junto-a quienes siempre se les negó la posibilidad de

8 Juan Carlos Scannone, "Sabiduría popular y teología inculturada”, Revista Stromata (1979): 7. la palabra, aquellos a quienes Gustavo Gutiérrez llamó los in-significantes. La fenomenología se puede presentar también como una maestra para ello, pues, mediante la epojé podemos suspender nuestros prejuicios eurocéntricos y aproximarnos al fenómeno de la vida que late en ese pueblo que es portador de lo que en verdad somos. Tal vez, nuestra tarea más importante es aproximar el método para interrogar esos orígenes constitutivos y poder extraer de ahí el nuevo mundo que necesitamos imaginar.

Debemos recordar que esta sabiduría popular a la que hemos hecho alusión como la constitutiva del ser latinoamericano es lo que Ignacio Ellacuría denominó con total acierto como el-lugar-que-da verdad. Es decir, la fuente de donde todo surge y a la que todo vuelve. Pues cuando nos solidarizamos con los oprimidos, se puede ver los efectos que la realidad histórica social crea en sus vidas, como lo podemos apreciar ahora mismo. Ellos no tienen necesidad de cubrir la verdad, como lo tienen que hacer los opresores y dominadores, por lo tanto, su posición en la realidad histórica nos capacita a ver lo que está realmente pasando. Aquí también la teoría husserliana de la intersubjetividad, esa capacidad de colocarse en el lugar del otro, nos puede develar, a partir de las experiencias de los pobres y oprimidos, la 
verdad que late en nuestro mundo de la vida y que clama por ser explicitada.

Dicho de otra manera, el lugarque-da-verdad es un arma contra la ideología, pues, mientras esta encubre, la otra puede auténticamente descubrir la realidad. Existe objetivamente una realidad distorsionada por la ideologización $\mathrm{y}$, al asumir el lugar que-daverdad, aquel que en clave fenomenológica podríamos interpretar como "nuestro mundo de la vida", uno puede hallarla libre de distorsiones. Para Ellacuría, se trata de "las mayorías populares", esto es, las "auténticas mayorías de la humanidad, es decir, la inmensa mayor parte de la humanidad." 9 Son constituidas por oposición a "unas minorías elitistas que, siendo la menor parte de la humanidad, utilizan en su provecho inmediato la mayor parte de recursos disponibles." ${ }^{10}$ Esto nos enseña que la opresión no es una ley natural o consecuencia de la pereza, sino que la opresión es consecuencia de "ordenamientos sociales históricos." 11 Estas mayorías populares tienen todo el poder que se necesita para cambiar la sociedad. Es decir, si habrá un verdadero cambio en la sociedad, va a venir de ellos; no necesitan la ayuda de una

9 Ignacio Ellacuria, "Universidad, derechos humanos y mayorías populares," en Ignacio Ellacuría, Escritos universitarios (San Salvador, El Salvador: Universidad Centroamericana Editores, 1999), 303.

10 Ibid.

11 Ibid. "vanguardia" o "partido" o algo así. Para Ellacuría "se debe confiar en las masas que se concientizan, se organizan, se movilizan y se alían, sin perder de vista su papel protagónico, que no necesita ser hegemónico." ${ }^{12}$

Esa verdad encarnada se expresa en el modo cómo el pobre, aquel que nada tiene excepto la precariedad de su vida, se aferra a ella con todas sus fuerzas. El cuentista peruano, Julio Ramón Ribeyro, en uno de sus cuentos más subyugantes, $\mathrm{Al}$ pie del acantilado, nos dice:

"Nosotros, los pobres, somos como la higuerilla, como esa planta salvaje que brota y se multiplica en los lugares más amargos y escarpados. Véanla cómo crece en el arenal, en el canto rodado, en las acequias sin riego, en el desmonte, alrededor de los muladares. Ella no pide favores a nadie, pide tan sólo un pedazo de espacio para sobrevivir. No le dan tregua ni el sol ni la sal de los vientos del mar, la pisan los hombres y los tractores, pero la higuerilla sigue creciendo. Propagándose, alimentándose de piedras y de basura. Por eso digo que somos como la higuerilla, nosotros, la gente del pueblo. Allí donde el hombre de la costa encuentra una higuerilla, allí hace

12 Ignacio Ellacuría, "La cuestión de las masas," en Ignacio Ellacuría, Veinte años de historia en El Salvador. (1969-1989). Escritos politicos, II (San Salvador, El Salvador: Universidad Centroamericana Editores, 1991), 791. 
su casa porque sabe que allí podrá también él vivir." 13

Pese a la adversidad de esta pandemia, hoy más que en ninguna otra época, debemos acompañar con el pensamiento condolido pero esperanzado al pobre y oprimido que con cada acto de su existencia nos muestra que vale la pena seguir viviendo. Él ha visto a la muerte a los ojos y con una sonrisa en el rostro le ha devuelto la imagen de la vida.

Sabemos que los oprimidos entre los oprimidos, los que se encuentran en la periferia de la periferia, son nuestros hermanos indígenas de las comunidades nativas de nuestro continente. Portadores de una sabiduría milenaria, sus voces han sido siempre acalladas. Es nuestro deber intelectual y moral darle cabida a esas voces llenas de sabiduría ancestral que constituyen, precisamente, el lugar-que-da-verdad, pues con su sola presencia y antigua resistencia nos interpelan acerca del tipo de convivencia que hemos constituido.

\section{4.- La voz de Nuestra América. Sumak Kawsay, rumbo a una nueva convivencia}

En las últimas décadas hemos podido escuchar, ver y aprender de la voz

13 Julio Ramón Ribeyro, La palabra del mudo (Lima: Editorial Planeta Perú, 2019), 297. de los pueblos ancestrales y su crítica a este modelo civilizatorio opresor de la verdad. Si queremos situarnos en una filosofía en perspectiva latinoamericana, es imprescindible entrar en un diálogo intercultural con nuestros pueblos originarios y aprender también de ellos.

Ahora que la vulnerabilidad y la incertidumbre de la vida se hacen cada vez más patentes, tal vez podamos volver la mirada a propuestas como las del Sumak Kawsay o buen vivir. Es decir, el modo de vida andino que compromete la vida del sujeto y su relación con su entorno natural, con su medio, lo que comprende tanto a los otros sujetos como a las plantas y animales. "Buen Vivir", desde esta perspectiva, hace referencia entonces no a una buena vida sino a un bien "vivir", es decir, "tener" una vida buena. Lo que implica el cuidado de los otros y de la naturaleza sin los cuales nuestra propia vida no sería posible.

En ese sentido, el Buen Vivir implica algo distinto a la concepción de "sociedad de bienestar" que se maneja en occidente. Sin embargo, esto no significa la renuncia a la modernización de la sociedad. Vivimos en un proceso histórico y de escalas tan universales que ya resulta imposible que se puedan negar los valiosos aportes del pensamiento de la humanidad, que, como veremos más adelante, están en sintonía con la construcción de un mundo 
armónico como se deriva de la filosofía del Buen Vivir. Por eso mismo, una de las tareas fundamentales recae en el diálogo permanente y constructivo de saberes y conocimientos ancestrales con el pensamiento occidental, en un proceso de continuada descolonización de la sociedad. El Buen Vivir, no solo como propuesta política, sino como filosofía de vida, todavía en construcción nos puede brindar un derrotero para una nueva convivencia.

El concepto de Sumak Kawsay o Buen Vivir implica una reinterpretación de los principales valores y principios que sustentan la cosmovisión indígena en la cual hay un equilibrio entre todos los seres del mundo. Ello incluye a los humanos, animales, plantas, astros, divinidades y espíritus. Cada ser es importante y merece ser respetado, ninguno debe ser tratado de modo utilitario o como instrumento. Es una visión del mundo que se centra en la relación entre el hombre y su entorno social y natural.

Desde esta perspectiva, el término Buen Vivir encierra las búsquedas de una alternativa al modelo neoliberal de desarrollo occidental que ha sido impuesto en Latinoamérica. El Buen Vivir aparece, así como la opción utilizada para conseguir otra manera de ser y estar en el mundo que no resulte perjudicial y pueda realmente solucionar los problemas que se dan, por ejemplo, en esta coyuntura.

Bajo esta concepción se debe tener en cuenta a todos los elementos que conforman la Pacha. En la cosmovisión andina debe haber una relación de complementariedad, correspondencia, movimiento cíclico del tiempo y reciprocidad. Se trata, además de la armonía entre los seres para que pueda darse una adecuada convivencia intercultural, intergeneracional e interbiótica. De ahí la necesidad de la complementariedad y solidaridad llevada a que exista una calidad de vida; la ayuda mutua entre los seres es lo que alimenta al Buen Vivir. El egoísmo individualista propio de la modernidad liberal queda seriamente cuestionado como modo de relacionarnos por la reciprocidad y solidaridad como componentes fundamentales en la concepción andina de la vida. Estas incluso van más allá de la relación entre humanos para extenderla a todo el entorno natural, incluyendo animales, plantas e incluso espacios geográficos como las montañas, lagos, ríos, etc.

El Sumak Kawsay está relacionado íntimamente con la "vida" con una visión cosmocéntrica y holista a diferencia de la visión de las propuestas occidentales dominantes modernas o contemporáneas. Ello quiere decir que los "entes inertes" tienen un valor importante para el mundo andino. Mujica 
al hablar de pacha, por ejemplo, la cataloga como "una categoría englobante [que] abarca 'todo lo que está a la vista' o aquello que puedo sentir que pasa' y 'lo que me envuelve', y da a una persona identidad propia." "'14 Este esquema civilizatorio se basa en la relación de complementariedad y reciprocidad entre todos los elementos y entes que se encuentran en el mundo, de ahí proviene la armonía y equilibrio del cosmos. Por ello, podemos entender a la Pacha como espacio, como tiempo y como subjetividad. Se trata de una "ontología Relacional" donde todo se encuentra vinculado: el pasado con el futuro, los animales con las plantas y los hombres, la naturaleza con lo artificial, la vida con la muerte, etc. Hay una clara diferencia entre la visión andina y la visión individualista en la cual se encuentra un fuerte antropocentrismo.

\section{Como nos enseña Esterman:}

"El 'Vivir Bien' amerindio mide la 'bondad' de cada elemento por la 'bondad' del todo, es decir: el 'vivir' depende fundamentalmente del 'con-vivir' en un sentido antropológico, ecológico (o ecosófico) y cósmico. No se puede -en sentido estricto- hablar de que alguien tiene 'buena vida' (un tercio de la humanidad), si otros/as viven en la miseria o son pisoteados/as por los

14 Luis Mujica, Pachamama Kawsan. Hacia una ecología andina (Lima: Pontificia Universidad Católica del Perú, 2016), 212. demás. Por tanto, el 'Vivir Bien’ no aspira a una 'mejor vida', porque en un mundo finito y limitado en cuanto a recursos, espacio y tiempo, el incremento de la calidad de vida de algunos/as conlleva al deterioro de la calidad de vida de otros/as" ${ }^{15}$

Estamos entonces ante una propuesta, que al igual que la fenomenología, supone una clara apuesta por la vida y su mantenimiento en el mundo. Hemos dicho que la fenomenología es una afirmación de la vida porque, como nos enseñó primero Husserl y luego Michel Henry, su tema único es el de la manifestación de la vida. Detengámonos un minuto sobre esta idea para ver luego su vinculación con la voz de los marginados de siempre, aquellos a quienes, hemos dejado dicho, deberíamos volver la mirada y la reflexión.

\section{Fenomenología de la vida y Sumak Kawsay}

Hemos visto que desde sus orígenes la fenomenología se levanta como una afirmación de la vida. Pero, en el siglo XX quien mejor intuyó este enorme aporte de Husserl fue el fenomenólogo Michel Henry. Para él la vida se encuentra íntimamente ligada con

15 Josef Estermann, "Crisis civilizatoria y Vivir Bien. Una crítica filosófica del modelo capitalista desde el allin kawsay/suma qamaña andino", Polis, Revista Latinoamericana n.33, Volumen 11 (2012): 14. 
la verdad, pues vivir significa ser. Así como no es posible definir el ser, tampoco es posible atrapar en un concepto a la vida, pues ella es lo más cierto que hay para cada viviente que, en efecto, se encuentra vivo gracias a ella. Por eso, es que la filosofía ha sido incapaz de pensarla, pues siempre ha querido definir y caracterizar al ser desde la exterioridad en oposición a la interioridad e intimidad de la subjetividad. Cuando más bien, la verdad de la vida se encuentra en la ipsiedad, en el pathos, el experimentarse a sí mismo viviendo, la vida es de este modo la verdad, no la teórica sino la praxis que significa estar efectivamente viviendo. La vida, por tanto, no se puede tratar como una abstracción, sino que se debe buscar en el viviente mismo.

La vida es concreta, real, efectiva. Hoy, que la muerte toca a nuestras puertas, vemos esto en toda su radicalidad. Henry nos invita a un abandono de la metafísica de la representación, lo que se encuentra en contra de la ipsiedad. El paradigma no puede ser entonces el de la conciencia, sino el de la afectividad, no se trata de ser consciente de mí mismo sino de experimentarme a mí mismo viviendo esa autoafectividad. La vida, nos dice, es lo que se siente y experimenta a sí mismo y esto sucede en la inmediatez de la autoafección.

La afectividad que ha sido prácticamente expulsada de la filosofía occidental cobra aquí un papel central. La afectividad es entonces la esencia de la afección, es la que acompaña la vivencia de mi temporalidad, el tiempo de mi vida que me otorga una tonalidad afectiva en mi tiempo de vivir. Esto hace de la vida algo pasivo. No se trata, como nos ha hecho creer el liberalismo, que nosotros somos los dueños de la vida o hacemos nuestra propia vida. Para Henry, la vida no es algo que hacemos sino algo que recibimos, es pasividad no actividad "pues tal es el misterio de la vida que el viviente es como extensivo al Todo de la vida en él, que todo en él es su propia vida. El viviente no se funda él mismo, tiene un fondo que es la vida, pero este fondo no es diferente a él, es la autoafección en la que se autoafecta y con la que, de esta forma, se identifica." ${ }^{16}$ Es decir, se abraza a la praxis de estar viviendo y si no abrazo esta praxis del estar viviendo entonces estoy abrazando la praxis del estar muriendo o matando.

El poder la vida no lo obtenemos en virtud de algo que hayamos hecho, nadie se ha dado a sí mismo la vida ni todas sus modalidades como el poder reír, pensar, amar, etc. Todos ellos vienen de la vida. Lo mismo sucede con el tiempo de vida que es la temporalidad del viviente, el tiempo en el cual permanezco con vida. El tiempo real es el tiempo presente del viviente. En

16 Michel Henry, Fenomenología material (Madrid: Ediciones Encuentro, 2009), 230. 
cambio, la vida es eterna y la autoafección es el modo como la vida se expresa en el viviente. La Vida es vida absoluta y la autoafección es como yo vivencio mi estar viviendo aquí que es estar viviendo en la eternidad de la vida. En todas estas modalidades está el lazo indisoluble entre la autoafección y la eternidad, ese es el tiempo real. La vida nunca se detiene ni se repite, es una eterna creación de lo nuevo, por eso, ningún virus podrá contra ella.

La vida singular de cada uno de nosotros es innovación. Nosotros no somos la vida, somos vivientes, ese es el índice, según Henry, que la intimidad esencial de cada viviente. Nosotros estamos viviendo quiere decir que la vida está aconteciendo desde su eternidad en la temporalidad de cada quien. Esto es lo que reclama una fidelidad absoluta a la vida, no renunciar a ella, ese es el imperativo existencial que hoy ante la amenaza de la muerte, que no podrá detener la vida, todos reclamamos.

Tenemos entonces que Henry nos muestra una concepción de la vida como pura autoafección y por eso mismo como pura inmanencia. Esto quiere decir que la vida se siente a sí misma en nuestra carne, o, para decirlo en otras palabras, que el modo que tenemos de sentir nuestra propia vida, es decir, el modo que tenemos de sentirnos vivos, es justamente a través de nuestra propia carne y sus afecciones, porque la vida, aunque esté naturalmente presente, parece muchas veces ausente, como si nos olvidáramos de ella, como si se ocultara tras las sombras de la cotidianidad. Y sucede entonces que vivimos sin notar siquiera la vida misma. Tal estado de aletargamiento, de somnolencia, de oscuridad en el que la vida no se nos hace patente, desaparece violentamente con la súbita aparición de una afección tal que, como un balde de agua fría, nos haga despertar haciéndonos presente nuestra propia vida; algo que llega con tal contundencia como ninguna otra cosa y que es imposible de ignorar como lo que estamos viviendo ahora.

Para Michel Henry el gozo y dolor son ejemplos indiscutibles de la autoafección de la propia vida. No obstante, el dolor corporal es el modelo más claro de la autoafectividad de la vida y un ejemplo de la inmanencia pura de una vivencia de la conciencia. Siguiendo las reflexiones de Vanesa Larios ${ }^{17}$ sobre el papel del dolor en la fenomenología de Henry, podemos decir que, este nos muestra, como lo está haciendo ahora, con su crudeza insoportable que es absolutamente inmanente a la conciencia, porque la experiencia del dolor es ya a la vez su objeto o, mejor dicho, que no hay como tal objeto alguno del dolor

17 Cfr. Vanesa Larios, "El dolor corporal. Reflexiones filosóficas en torno a Michel Henry", Open Insight Volumen II n. 2 (julio 2011): 131-143. 
fuera del dolor mismo por el hecho de que cuando el dolor se sufre, sencillamente se sufre, o para decirlo de otra manera: el dolor duele, se deja sentir y se reconoce como tal desde el instante en el que aparece repentinamente.

La fenomenología de Henry nos enseña que cuando sufrimos, padecemos o nos vemos afectados por algo, que puede ser físico o anímico, como sucede con el dolor ajeno, nuestro ser se vuelve un ser pasivo y tal pasividad significa que ninguna impresión surge de manera activa, es decir, que ninguna impresión se provoca ella misma, sino que sencillamente se recibe sin opción de rehuir a ella. Todo nos es donado, hemos recibido la vida en nuestra carne, simplemente no hemos podido rehuir a su donación, así como tampoco podemos rehuir a la posibilidad de sufrir dolor que nos acecha a cada instante, nuestra carne está tan expuesta al dolor como al sol de cada mañana; es el llamado de la vida, aquello que llama nuestra atención tan brutalmente que nos es imposible ignorar. El dolor nuestro y de los otros nos devuelve a la vida al mismo tiempo que atenta contra ella, es el límite ante el cual tambalea toda nuestra existencia, la sacude cruelmente, al punto que quisiéramos salir huyendo de nuestra carne, no estar conscientes de nuestra existencia, de nuestra vulnerabilidad, nuestra debilidad.
Sin embargo, queda la esperanza de que el dolor pase y entonces nos reconciliamos con la vida, incluso nos aferramos más a ella. El terror ante el dolor es terror ante el sentimiento de que la vida es dolorosa, frágil, ante la certeza de que la existencia es sufrimiento; pero es justo ante esta certeza que la vida se revela para cada uno como aquello más preciado, como aquello a lo que atendemos con más cuidado. Sin embargo, queda claro que vida y dolor, gozo y sufrimiento son parte de un continuo que nos hace saber que el hecho primordial de la vida finalmente vencerá sobre la muerte.

Lo que nos quiere enseñar la fenomenología de Henry, es que, pese a nuestra vulnerabilidad e incertidumbre, la vida es lo más cierto que tenemos y que debemos aferrarnos a ella, no solo porque sea una donación sino porque es lo que permite que nos mantengamos y nos podamos sostener los unos a los otros en una relación de comunidad, pues "toda comunidad es una comunidad de vivientes" y la esencia misma de la comunidad es la vida. Por eso, no podemos sustraernos a ella.

Esta imposibilidad de sustraernos a la comunidad en la que la vida se manifiesta nos lleva también a condolernos con los otros, con aquellos que están siendo víctimas no solo de la pandemia, sino de la tremenda 
desigualdad de nuestras sociedades. De hecho, el propio Henry nos dice:

"En tanto en cuanto la esencia de la comunidad es la afectividad, no se limita sólo a los humanos sino que comprende todo lo que se haya definido en sí por el Sufrir primitivo de la vida y, así, por la posibilidad del sufrimiento. Podemos sufrir con todo lo que sufre: hay un pathos-con que es la forma más amplia de toda comunidad concebible." 18

Se trata de una comunidad que no se circunscribe solo a los seres humanos, como la de la ontología relacional del Sumak Kawsay, sino que abarca a la totalidad de los seres vivientes y a la naturaleza en su conjunto, tal como desde hace milenios ya lo intuyeron las comunidades originarias de nuestro continente. Vemos cómo cuando avanzamos a las profundidades mismas de la descripción de lo más originario que tenemos, como la vida, nos percatamos de las coincidencias acerca de la experiencia humana.

Por eso, retomando lo ya señalado líneas arriba sobre el pensar en perspectiva latinoamericana y desde el lugar-que-da-verdad, deberíamos conducirnos a una reflexión radical sobre el tipo civilizatorio por el que occidente ha optado y que ahora, lo podemos constatar, trae la posibilidad de una muerte global, sobre todo de los más excluidos. Si algo nos ha enseñado esta pandemia es que solo algunos tienen Corona y a la gran mayoría tan solo les queda el virus.

En ese sentido, la filosofía entendida como un permanente diálogo de culturas no solo se constituye como una afirmación clara en favor de la vida, sino que también se coloca del lado de todos los que sufren. Si sabemos encausar nuestra reflexión, sacarla de la comodidad de la exégesis, el esoterismo, y conducirla al lado de los que más están sufriendo en estos momentos tan adversos para la humanidad, entonces, podremos hacer justicia al motivo más profundamente ético al que nos llama la filosofía.

\section{Consideraciones finales}

Sin renunciar a su universalidad, la filosofía es también un saber situado y contextual. Por esa razón, la fenomenología, como la primera de las filosofías, tiene mucho que decirnos acerca del modo de aproximarnos a la experiencia universal del sentido o sin-sentido ante la vida y la muerte. Pero, más aún, tiene mucho que decirnos acerca del modo cómo se da la experiencia filosófica entre los latinoamericanos a los que nos incumbe el deber de hacer filosofía en diálogo permanente y desde la sabiduría ancestral. 
Por tal razón, Husserl nos enseña que:

"Nosotros, los seres humanos del presente, formados a lo largo de este desarrollo, nos hallamos en el mayor peligro de sumergirnos en el diluvio escéptico y con ello renunciar a nuestra propia verdad. Tomando conciencia de nosotros en este desamparo, nuestra mirada vaga hacia la historia de nuestra humanidad actual. Sólo podemos alcanzar la comprensión de nosotros mismos y por ese medio lograr un sostén interior, mediante el esclarecimiento de su sentido unitario, que le es innato desde su origen, con la tarea nueva instituida que como fuerza impulsiva mueve la búsqueda filosófica". ${ }^{19}$

El peor de los peligros que hoy afrontamos es el de dejarnos arrastrar por este "diluvio escéptico", pues la renuncia a la verdad implica la renuncia a nuestra propia humanidad. Hoy cuando la tentación del descrédito y el cuestionamiento a todo tipo de verdad se encuentra tan a la moda es nuestro deber recuperar la impronta de no renunciar a una vida racional. Con el matiz que por racional no debe entenderse exclusivamente un tipo específico de racionalidad, sino las diferentes maneras de ser racional ${ }^{20}$ que nos llevan a

19 Husserl, Crisis, 58.

20 Cfr. Villanueva, Las diferentes maneras de ser racional, 114-125 alcanzar una comprensión de nosotros mismos desde nuestra especificidad.

La actual pandemia ha desatado una profunda crisis que se puede abordar desde diferentes perspectivas, político, económico, social y hasta civilizatorio. Lo que enfrentamos no se trata solo de un problema de salud, sino de un fenómeno de orden estructural. Nunca antes una pandemia asoló de esta manera al planeta entero y no lo hizo porque nunca antes la humanidad logró constituir un modelo globalizador y hegemónico como el que tenemos. Esto nos lleva a pensar, por otro lado, en la dicotomía política que hemos vivido en la que los estados han pedido y obligado a un gran sector de la humanidad a coactar su libertad guardando cuarentenas militarizadas, en la que el valor más importante de la sociedad democrática, a saber, la libertad también se veía amenazada por la muerte.

También nos ha planteado un dilema ético-existencial, ante el sobrepasamiento de los sistemas de salud, se plantea la imposible elección de a quién salvar la vida, a los más ancianos o los más jóvenes, así como a quienes se les dará antes la vacuna a los de los países ricos o a los de los países pobres. También es posible señalar el dilema epistémico que nos coloca ante la pregunta de si seguir los dictados de la ciencia o los de la sabiduría ancestral 
al momento de abordar la enfermedad y su cura.

Todo esto plantea problemas que la filosofía no puede ni debe eludir. Nunca antes como ahora el pathos del ser humano se ha mostrado como el de un ser desconcertado ante su radical finitud. Por ello, lo que se necesita es lo que la fenomenología viene proponiendo desde su fundación: una renovación de la razón. No una doctrina o un sistema categorial, sino una manera creativa de aproximarse a la compleja y variopinta experiencia humana.

En esta multiplicidad y diversidad de la experiencia humana es donde propuestas de mundos de la vida como el andino, a través del Sumak Kawsay, cobran especial importancia pues nos muestran que existen otros modos posibles de vivir en armonía con la naturaleza y con los otros. Desde nuestra perspectiva tanto el pensar ancestral latinoamericano como la fenomenología en su vertiente intercultural implican una apuesta por la vida. Esperamos que hayamos podido mostrar en estas páginas cómo, desde la reivindicación andina de una ontología relacional pasando por la fenomenología de la vida henryana y el mundo de la vida husserliano, todas son voces que nos hablan de la esperanza en la vida y la apuesta por la necesidad de no renunciar a una racionalidad renovada que abarque y comprenda todos los diferentes niveles de la experiencia.

\section{Bibliografía}

Ellacuría, Ignacio. 1991. "La cuestión de las masas," en Ignacio Ellacuría, Veinte años de historia en El Salvador. (1969-1989). Escritos politicos, II. San Salvador, El Salvador: Universidad Centroamericana Editores.

1999. Universidad, derechos humanos, y mayorías populares, en Ignacio Ellacuría, Escritos universitarios. San Salvador, El Salvador: Universidad Centroamericana Editores.

Estermann, Josef. 2012. Crisis civilizatoria y Vivir Bien. Una crítica filosófica del modelo capitalista desde el allin kawsay/suma qamaña andino. Polis, Revista Latinoamericana, Volumen 11, $\mathrm{N}^{\circ}$ 33: 149-174.

Henry, Michel. 2009. Fenomenología material. Madrid: Ediciones Encuentro.

Husserl, Edmund. 2008. La crisis de las ciencias europeas y la fenomenología trascendental. Buenos Aires: Prometeo Libros.

Larios, Vanesa. 2011. El dolor corporal. Reflexiones filosóficas en torno a Michel Henry. Open Insight Volumen II $\mathrm{N}^{\mathrm{O}} 2$, (julio): 129-144. 
Lerner Febres, Salomon. 2004. La rebelión de la memoria. Lima: Idhepucp.

Merleau-Ponty, Maurice. 1964. Signos. Barcelona: Seix Barral.

Mujica, Luis. 2016. Pachamama Kawsan. Hacia una ecología andina. Lima: Pontificia Universidad Católica del Perú.

Ribeyro, Julio Ramón. 2019. La palabra del mudo. Lima: Editorial Planeta Perú.

Sacannone, Juan Carlos. 1979, Sabiduría popular y teología inculturada. Revista Stromata Vol. 35 n.1/2 (enero-junio): 3-18.
1980. Un nuevo punto de partida en la filosofía latinoamericana. Revista Stromata. Vol. 36 n. 1/2 (enerojunio): 25-47.

Thorndike, Guillermo. 1988. La revolución imposible. Lima: Mosca Azul Editores.

Villanueva Barreto, Jaime. 2006. Las diferentes maneras de ser racional: Doxa y episteme en la fenomenología de Husserl. La Lámpara de Diógenes (enerojulio, volumen $7, \mathrm{~N}^{\circ}$ 12-13): 114-125. 